\title{
A Fluorescent Cy7-Mercaptopyridine for the Selective Detection of Glutathione over Homocysteine and Cysteine
}

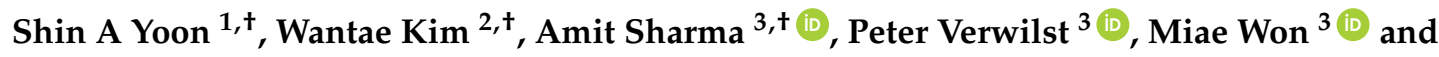 \\ Min Hee Lee ${ }^{1, *}$ \\ 1 Department of Chemistry, Sookmyung Women's University, Seoul 04310, Korea; \\ dbstlsdk23@sookmyung.ac.kr \\ 2 School of Chemical and Biological Engineering, Seoul National University, Seoul 151-742, Korea; \\ wtkim223@naver.com \\ 3 Department of Chemistry, Korea University, Seoul 02841, Korea; amitorg83@gmail.com (A.S.); \\ peterverwilst@hotmail.com (P.V.); miaewon@korea.ac.kr (M.W.) \\ * Correspondence: minheelee@sookmyung.ac.kr; Tel.: +82-2-2077-7815 \\ + These authors contributed equally to this work.
}

Received: 31 July 2018; Accepted: 30 August 2018; Published: 1 September 2018

\begin{abstract}
We describe a near-infrared (NIR) fluorescent probe 1 for the selective detection of GSH over Hcy and Cys under physiological conditions. Probe 1 was composed of Cy7 as a NIR dye and 2-mercaptopyridine as a GSH-reactive site and fluorescence quencher. In the presence of GSH, the 2-mercaptopyridine functionality of probe $\mathbf{1}$ was replaced by the thiolate group of GSH through a nucleophilic substitution reaction with a fluorescence increase at $818 \mathrm{~nm}$. The probe was found to be highly selective for GSH over Hcy, Cys, and other tested potential interferants, including ROS and metal ions. In addition, probe 1 successfully displayed fluorescence changes in response to changing the GSH concentrations in MDA-MB-231 cells in the presence of external agents i.e., $\mathrm{N}$-acetyl-L-cysteine (NAC; as GSH inducer) or buthionine sulfoximine (BSO; as GSH inhibitor). We envision that probe 1 will serve as a promising sensing tool for monitoring the changes of the GSH level and the understanding of the roles of GSH under physiological and pathological conditions.
\end{abstract}

Keywords: NIR fluorescent probe; Cy7 dye; glutathione (GSH); 2-mercaptopyridine

\section{Introduction}

Bio-thiols, e.g., glutathione (GSH), cysteine (Cys), and homocysteine (Hcy), play important roles in maintaining the redox status of biological systems [1,2]. In humans, GSH is the most abundant non-protein cellular thiol, with concentrations ranging from 0.5 to $15 \mathrm{mM}$ [3]. GSH with its oxidized partner (GSSG) is involved in several crucial biological processes, including xenobiotic metabolism, gene regulation, signal transduction, growth, stress responses, immune responses [4-6]. These functions are dynamically controlled by the intracellular distribution and concentration of GSH. In addition, abnormal levels of GSH are associated with cancer, heart disorders, aging and other diseases. Consequently, the detection and imaging of intracellular GSH is of great demand for the deep understanding of GSH-related pathophysiological investigations, diagnosis and identification of related diseases.

To date, a number of artificial fluorescent probes that can detect bio-thiols with high temporal and spatial resolution in living systems have been exploited [7-10]. However, most of the probes cannot discriminate GSH from Hcy/Cys. Because their sensing mechanisms, such as Michael addition, cleavage of sulfonamide and sulfonate esters, and disulfide exchange, etc., are based on nucleophilicity of thiols. In addition, most probes were constructed by fluorophores, e.g., coumarin, naphthalimide, 
rhodamine, that absorb and emit the lights in the UV-Vis region, which can damage living cells and be affected by the autofluorescence of biomolecules. Recently, Yang and his co-workers exploited a monochlorinated BODIPY-based probe for discrimination of GSH over Hcy/Cys [11]. The chlorine of BODIPY was replaced by thiolates of GSH and Hcy/Cys, and subsequently the amino groups of Hcy/Cys, but not GSH, replaced the sulfur to form amino-substituted BODIPY, hence resulting in different photophysical changes towards GSH and Hcy/Cys. The chemical ligation was extensively employed as a powerful method for the discrimination of GSH over Hcy/Cys [12-17]. In addition, the near-infrared (NIR) fluorescent dyes are good candidates for detecting GSH as they can provide several merits, such as no interference from the auto-fluorescence of biomolecules, minimization of cellular photodamage, etc., in the field of bioimaging research [18-25]. Particularly, cyanine-based NIR dyes are suitable for bioimaging due to their proper excitation and emission wavelengths as well as their biocompatibility [26]. However, the NIR fluorescent probes for the selective detection of GSH over Hcy and Cys are still rarely reported [18-20].

In the current work, we present a NIR fluorescent probe 1 that can selectively detect GSH over Hcy and Cys under physiological conditions. Probe $\mathbf{1}$ was comprised of Cy7 as a NIR fluorescent dye and 2-mercaptopyridine as a GSH-reactive site and fluorescence quencher. As proposed in Scheme 1, probe 1 displayed a weak fluorescence at $818 \mathrm{~nm}$ (excitation wavelength $=720 \mathrm{~nm}$ ). However, in the presence of GSH, the 2-mercaptopyridine of 1 was replaced by nucleophilic substitution of a thiolate of GSH to form sulfur-substituted Cy7, 1-GSH, displaying a strong fluorescence at $818 \mathrm{~nm}$. However, in the presence of Hcy/Cys, 1 reacted with Hcy/Cys to form sulfur-substituted intermediates, and subsequently the amino groups of Hcy/Cys replaced the sulfur. This rearrangement furnished an amino-substituted Cy7 dyes, 1-Hcy/1-Cy, exhibiting a weak fluorescence at $807 \mathrm{~nm}$. In addition, a change of the GSH levels in living cells was achieved by probe $\mathbf{1}$ with confocal microscopy. Thus, $\mathbf{1}$ could be used for the discrimination of GSH over Hyc/Cys in live human cells.

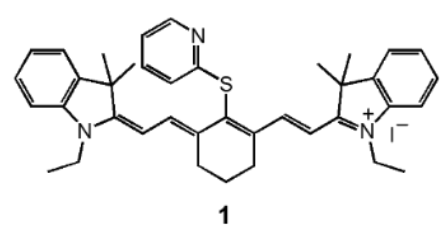

A Weak Fluorescence at $818 \mathrm{~nm}$

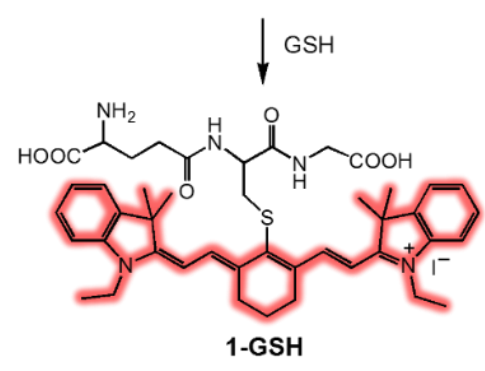

A Strong Fluorescence at $818 \mathrm{~nm}$
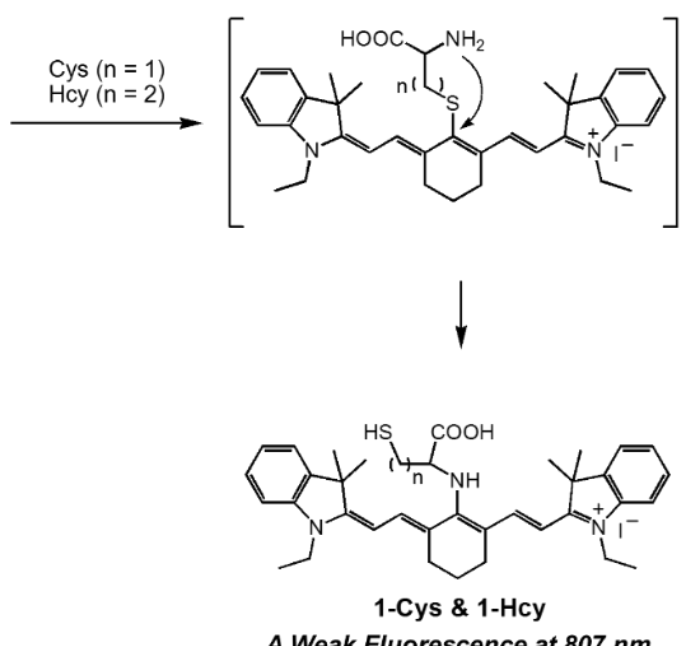

Scheme 1. Proposed detection mechanism of $\mathbf{1}$ to GSH over Hcy/Cys.

\section{Materials and Methods}

\subsection{Materials and Instrumentation}

All fluorescence and UV-Vis absorption data were collected using RF-6000 (Shimadzu Corporation, Kyoto, Japan) and UV-2600 (Shimadzu Corporation) spectrophotometers, respectively. ${ }^{1} \mathrm{H}-(500 \mathrm{MHz})$ and ${ }^{13} \mathrm{C}-\mathrm{NMR}(125 \mathrm{MHz})$ spectra were collected in DMSO- $d_{6}$ (Cambridge Isotope Laboratories, Cambridge, MA, USA) on a Bruker spectrometer (Bruker, Billerica, MA, USA). Silica gel 60 (Merck, Darmstadt, Germany, 0.063-0.2 mm) was used for column chromatography. Analytical thin layer chromatography was performed using Merck $60 \mathrm{~F}_{254}$ silica gel (precoated sheets, $0.25 \mathrm{~mm}$ thick). 
All reactions were carried out under nitrogen atmosphere. All reagents including metals such as chloride salts of $\mathrm{Na}^{+}, \mathrm{Mg}^{2+}, \mathrm{K}^{+}, \mathrm{Ca}^{2+}, \mathrm{Ni}^{2+}, \mathrm{Fe}^{2+}, \mathrm{Co}^{2+}, \mathrm{Zn}^{2+}, \mathrm{Ba}^{2+}, \mathrm{Pb}^{2+}, \mathrm{Cd}^{2+}, \mathrm{Ag}^{+}, \mathrm{Hg}^{2+}, \mathrm{Fe}^{3+}$, $\mathrm{Cu}^{2+}$, and $\mathrm{Cu}^{+}$ions, thiols such as cysteine (Cys), homocysteine (Hcy), glutathione (GSH), and other chemicals for synthesis, buffer solution were purchased from Aldrich (Aldrich, St. Louis, MO, USA), Alfa (Alfa, Heysham, LA3 2XY, United Kingdom), or TCI (TCI, Tokyo, Japan) and used as received. All solvents were analytical reagents. DMSO for spectroscopic experiments was HPLC reagent grade without fluorescent impurities and water was deionized water.

\subsection{UV-Vis Absorption and Fluorescence Spectroscopic Methods}

Stock solutions of synthetic compounds were prepared in DMSO. Different $\mathrm{pH}$ buffer solutions were prepared by using literature procedures [27]. Stock solutions of chloride salts of metal ions were prepared in water. Stock solutions of reactive oxygen species (ROS) were prepared by using literature procedures [28]. Stock solutions of thiols were prepared in $10 \mathrm{mM} \mathrm{pH} \mathrm{7.4} \mathrm{HEPES} \mathrm{buffer} \mathrm{solution.} \mathrm{Samples} \mathrm{for} \mathrm{absorption}$ and emission measurements were contained in quartz cuvettes ( $4 \mathrm{~mL}$ volume). All data were obtained in HEPES buffer $(10 \mathrm{mM}, \mathrm{pH} 7.4)$ containing $1 \%(v / v)$ of DMSO after incubation of $1 \mathrm{~h}$ at room temperature. Excitation was provided at $720 \mathrm{~nm}$ with excitation and emission slit widths being set at $10 \mathrm{~nm}$.

\subsection{Quantum Yield $\left(\Phi_{F}\right)$ Measurement}

Indocyanine green dye $\left(\Phi_{\mathrm{F}} 0.13\right.$ in DMSO) was used as a reference compound for determination of the quantum yields [29]. The compound displays absorption and fluorescence with a maximum wavelength at 795 and $883 \mathrm{~nm}$, respectively. Quantum yields were calculated by the comparison of the ratio between the areas for the fluorescence bands of the probe and the reference dye. The measurements were taken at the same absorbance intensity for both of the probe and the reference dye.

\subsection{Cell Culture}

MDA-MB-231, human breast carcinoma cell line, was obtained from the Korea Cell Line Bank. Cells were grown in modified Eagle's media (MEM) (Hyclone, Logan, UT, USA) supplemented with $10 \%$ heat inactivated fetal bovine serum (Hyclone), $100 \mathrm{IU} / \mathrm{mL}$ penicillin and $100 \mu \mathrm{M} / \mathrm{mL}$ streptomycin (Hyclone). Cells were cultured at $37^{\circ} \mathrm{C}$ in a humidified $5 \% \mathrm{CO}_{2}$ atmosphere.

\subsection{Cell Viability}

Approximately $2 \times 10^{4}$ cells were seeded on a 96 well microplate (SPL Life Science, Pocheon-si, Gyeonggi-do, Korea) and incubated for $24 \mathrm{~h}$. After incubation, the cells were treated with water as a control and probe $\mathbf{1}$ for $6 \mathrm{~h}$. To analyze the cell viability of cells in the presence of the probes, we performed using a CytoTox96 ${ }^{\circledR}$ Non-Radioactive Cytotoxicity Assay Kit (Promega, Madison, WI, USA) following the manufacturer's instructions. The absorbance level was measured by a SPECTRA MAX GEMINI EM microplate reader (Molecular Devices, San Jose, CA, USA). The wavelength was set at $490 \mathrm{~nm}$. Cell viability assay were performed in triplicate, and the viability (\%) was expressed as a percentage of measured absorbance relative to the control cells.

\subsection{Confocal Microscope Imaging Analysis}

Approximately, cells $\left(5 \times 10^{4}\right.$ cells) seeded on 35-mm glass bottom confocal dishes (SPL Life Science) and stabilized for $24 \mathrm{~h}$. Cells were pretreated with the $100 \mu \mathrm{M}$ buthionine sulfoximine (BSO) as a GSH synthesis inhibitor, and $3 \mathrm{mM} \mathrm{N}$-acetyl-L-cysteine (NAC) as a ROS scavenger for $12 \mathrm{~h}$ and then incubated with probe $\mathbf{1}\left(10 \mu \mathrm{M}\right.$ in DMSO) at $37^{\circ} \mathrm{C}$ in $5 \% \mathrm{CO}_{2}$ for $2 \mathrm{~h}$. Fluorescence microscope images of probe 1-labeded cells were obtained with a confocal laser scanning microscope (CLSM, Carl-Zeiss LSM 700 Exiciter, Heidelberg, Germany) by excited at $633 \mathrm{~nm}$ with a He/Ne optics laser source and emission was collected by a $640-690 \mathrm{~nm}$ band pass filter. 


\subsection{Computational Study}

The geometry and associated energies of the tetrahedral intermediates of probe 1 with GSH and Cys were calculated using the $\omega$ B97XD functional [30] at the 6-31+G(d) level of theory [31-34] with the default IEFPCM variant of the PCM model of water [35] using the Gaussian 16 software suite [36]. The structural optimizations and frontier orbital calculations of molecular orbitals of $\mathbf{1}-\mathbf{H}^{+}$, Cy7-SMe and Cy7-NHMe were performed using the PBE0 functional [37] at the 6-311G(2d,p) level of theory $[31,32,34]$ using the default IEFPCM variant of the PCM model of water. Input files and structure and molecular orbital visualizations were generated using Gabedit 2.5.0 [38].

\subsection{Synthesis}

Probe 1 was prepared by the synthetic route depicted in Scheme 2. Briefly, compound 2 was reacted with 2-mercaptopyridine in the presence of $\mathrm{NaH}$ as a base in DMF, which produced 1 in $70 \%$ yield. The chemical structure of $\mathbf{1}$ was identified by ${ }^{1} \mathrm{H}$ and ${ }^{13} \mathrm{C}$ NMR spectroscopy, as well as ESI-MS spectrometry (Figures S10-S12).

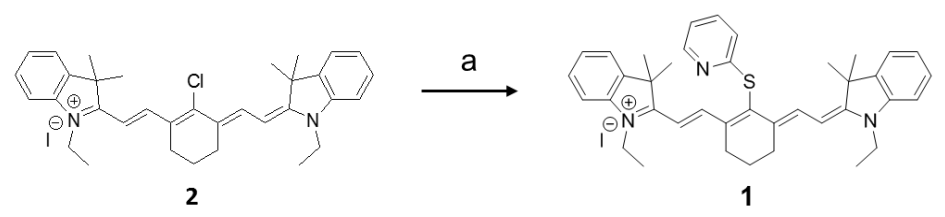

Scheme 2. Synthetic route for 1. Reaction conditions: (a) 2-mercaptopyridine, $\mathrm{NaH}, \mathrm{DMF}, 0{ }^{\circ} \mathrm{C}, 2 \mathrm{~h}$.

\subsubsection{Synthesis of 2}

Cy7 dye (2) was prepared according to the previously published procedure [39].

\subsubsection{Synthesis of 1}

To a single necked round bottom flask under an inert atmosphere, $\mathrm{NaH}(11 \mathrm{mg}, 48 \mathrm{mmol})$ was added to a cold solution of DMF ( $10 \mathrm{~mL}$ ) and stirred for $15 \mathrm{~min}$. 2-Mercaptopyridine ( $53 \mathrm{mg}, 0.48 \mathrm{mmol})$ was added to the mixture dropwise and stirring was continued for additional $30 \mathrm{~min}$. Finally, DMF $(5 \mathrm{~mL})$ solution of $\mathbf{2}(200 \mathrm{mg}, 0.32 \mathrm{mmol})$ was added dropwise and further stirred at $0{ }^{\circ} \mathrm{C}$ for additional $1 \mathrm{~h}$. After completion, the reaction was quenched with brine, extracted with dichloromethane (DCM) $(3 \times 50 \mathrm{~mL})$. The organic extract was dried over anhydrous sodium sulfate, filtered, concentrated and purified by a silica gel column chromatography $(5-10 \% \mathrm{MeOH}$ in DCM) to obtain 1 (160 mg, 70\% yield) as a blue powder. ${ }^{1} \mathrm{H}-\mathrm{NMR}\left(\mathrm{DMSO}-d_{6}, 28{ }^{\circ} \mathrm{C}\right): \delta 1.37(\mathrm{t}, 6 \mathrm{H}, J=7.2 \mathrm{~Hz}), 1.46(\mathrm{brs}, 12 \mathrm{H}), 2.06$ (s, $2 \mathrm{H}), 2.82(\mathrm{~m}, 4 \mathrm{H}), 4.18(\mathrm{q}, 4 \mathrm{H}, J=7.2 \mathrm{~Hz}), 6.32(d, 2 \mathrm{H}, J=14.2 \mathrm{~Hz}), 7.11-7.13(\mathrm{~m}, 2 \mathrm{H}), 7.15-7.18(\mathrm{~m}, 8 \mathrm{H})$, 7.64-7.67 $(\mathrm{m}, 1 \mathrm{H}), 8.38-8.39(\mathrm{~m}, 1 \mathrm{H}), 8.78(\mathrm{~m}, 2 \mathrm{H}, J=14.2 \mathrm{~Hz})$ ppm. ${ }^{13} \mathrm{C}$ NMR (DMSO- $\left.d_{6}, 28{ }^{\circ} \mathrm{C}\right): \delta 11.2$, 20.7, 25.9, 26.6, 38.9, 49.1, 101.0, 110.6, 120.7, 122.1, 125.1, 128.5, 128.6, 133.4, 138.1, 141.3, 141.7, 145.8, 145.8, 149.2, 172.3 ppm. ESI-MS: $m / z \mathrm{C}_{39} \mathrm{H}_{44} \mathrm{~N}_{3} \mathrm{~S}^{+}$calcd. 586.33, found $586.30[\mathrm{M}]^{+}$.

\section{Results and Discussion}

\subsection{Photophysical Study of $\mathbf{1}$ for the Detection of GSH over Cys/Hcy}

We investigated UV-Vis absorption and fluorescence changes of $\mathbf{1}$ to various metal ions, anions, reactive oxygen species (ROS), and thiols in HEPES buffer $(10 \mathrm{mM}, \mathrm{pH} 7.4)$ containing $1 \%(v / v)$ of DMSO. As shown in Figure 1a,b, probe 1 exhibited absorption and fluorescence bands at 790 and $818 \mathrm{~nm}$, respectively. However, in the presence of GSH, the absorption at $790 \mathrm{~nm}$ was greatly enhanced with increased fluorescence intensity at $818 \mathrm{~nm}$. In contrast, in presence of Hcy/Cys, the absorption of 1 at $790 \mathrm{~nm}$ was slightly diminished, while the fluorescence intensity distinctively decreased along with a shift of wavelength maximum from 818 to $807 \mathrm{~nm}$. The quantum yield $\left(\Phi_{\mathrm{F}}\right)$ of 1 was measured 
in the absence and presence of GSH, Cys, and Hcy, resulted in 0.006, 0.016, 0.003, and 0.011 for 1, 1-GSH, 1-Cys, and 1-Hcy, respectively.

We next tested the fluorescence response of 1 towards other biological analytes, including ROS (e.g., ${ }^{\bullet} \mathrm{O}_{2}{ }^{-}, \bullet^{\bullet} \mathrm{OH},{ }^{t} \mathrm{BuO}^{\bullet}, \mathrm{H}_{2} \mathrm{O}_{2},{ }^{\mathrm{t}} \mathrm{BuOOH}, \mathrm{ClO}^{-}$) and metal ions (e.g., $\mathrm{Na}^{+}, \mathrm{K}^{+}, \mathrm{Mg}^{2+}, \mathrm{Ca}^{2+}, \mathrm{Fe}^{2+}, \mathrm{Co}^{2+}$, $\mathrm{Zn}^{2+}, \mathrm{Fe}^{3+}, \mathrm{Cu}^{2+}, \mathrm{Cu}^{+}$) (see also Figures S1 and S2). The fluorescent increase of $\mathbf{1}$ observed for GSH was not observed upon the addition of any of the potential interferants tested (Figure 1c). In addition, probe 1 showed the fluorescence increase for GSH even in the presence of other analytes except for iron ions and $\mathrm{ClO}^{-}$(Figure S3). These results indicate that $\mathbf{1}$ can provide a highly selective fluorescence response at $818 \mathrm{~nm}$ to GSH over Hcy/Cys and other potential interferants.

a)

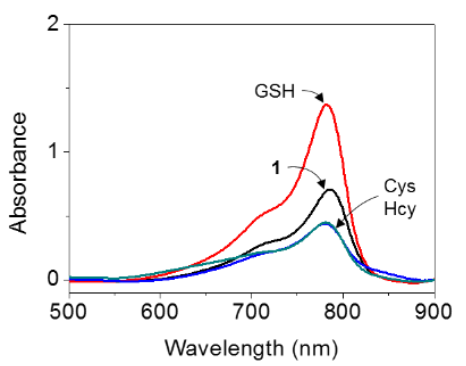

c)

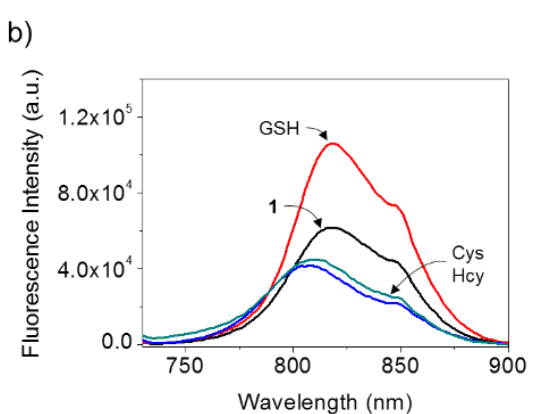

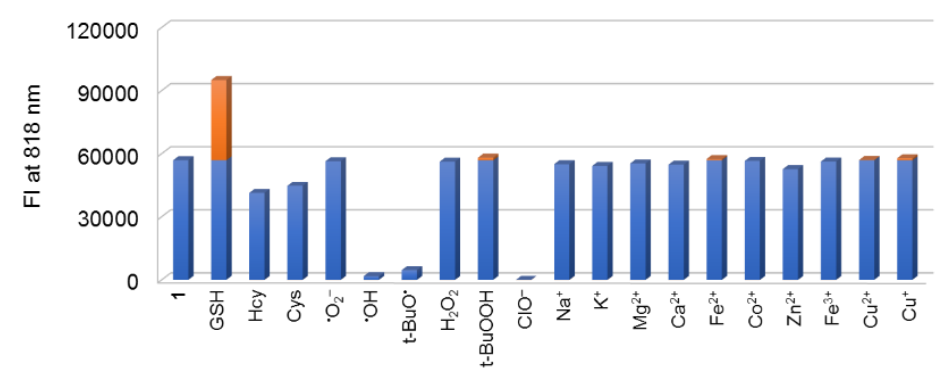

Figure 1. (a) UV-Vis absorption and (b) fluorescence spectra of $\mathbf{1}(10 \mu \mathrm{M})$ in presence GSH, Hcy and Cys (10 mM, respectively). (c) Relative fluorescence intensity at $810 \mathrm{~nm}$ of $\mathbf{1}$ to thiols, ROS, and metal ions. All data were obtained in HEPES buffer $(10 \mathrm{mM}, \mathrm{pH} 7.4)$ containing $1 \%(v / v)$ of DMSO after incubation of $1 \mathrm{~h}$ at room temperature. The excitation wavelength was affected at $720 \mathrm{~nm}$.

To get insight into the photophysical changes of $\mathbf{1}$ to GSH, probe $\mathbf{1}$ was treated with different concentrations of GSH. As the concentration of GSH increased, 1 exhibited a gradual increase in the absorption at $790 \mathrm{~nm}$ as well as a visual color change from light green to deep green (Figure 2a, inset). On the other hand, the fluorescence intensity of probe $\mathbf{1}$ at $818 \mathrm{~nm}$ was gradually increased and saturated at $10 \mathrm{mM}$ of GSH as the increase of GSH concentration (Figure 2b,c). These changes depending on the GSH concentration might be due to a formation of 1-GSH, as depicted in Scheme 1. In addition, the change in fluorescence intensity (FI) at $818 \mathrm{~nm}$ was plotted as [GSH] concentrations of

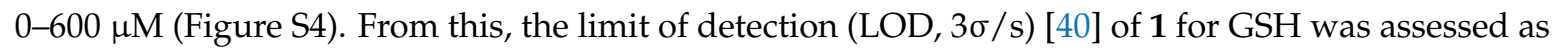
$97 \mu \mathrm{M}$, which is in the range of biological concentration of GSH.

By contrast, upon increasing concentrations of Cys or Hcy, probe $\mathbf{1}$ exhibited a significant decrease in the absorption at $790 \mathrm{~nm}$ and showed a fluorescence decrease as well as the fluorescence wavelength shift from 818 to $807 \mathrm{~nm}$ (Figures S5 and S6). This change might result from the formation of the amino-substituted Cy7 dyes, 1-Hcy/1-Cys, as suggested in Scheme 1, unlike GSH.

Moreover, fluorescence changes of $\mathbf{1}$ in the presence of GSH were monitored over the course of time. Upon adding $10 \mathrm{mM}$ of GSH to a solution of 1, the fluorescence intensity at $818 \mathrm{~nm}$ was increased and saturated within $1 \mathrm{~h}$ (red line in Figure 2d). By contrast, in the absence of GSH, $\mathbf{1}$ showed a negligible fluorescence change (black line in Figure 2d). On the other hand, in the presence of Cys, 
the fluorescence intensity of $\mathbf{1}$ at $818 \mathrm{~nm}$ was gradually decreased in $60 \mathrm{~min}$ (Figure S7). In the case of Hcy, 1 showed a rapid decrease in the fluorescence intensity at $818 \mathrm{~nm}$ within $4 \mathrm{~min}$, followed by the gradual enhancement in fluorescence up to $60 \mathrm{~min}$. The two-phase fluorescence change of $\mathbf{1}$ to Hcy is probably due to the formation of a sulfur-substituted Cy7 intermediate followed by the rearrangement of the resulting amino-substituted Cy7, 1-Hcy.

a)

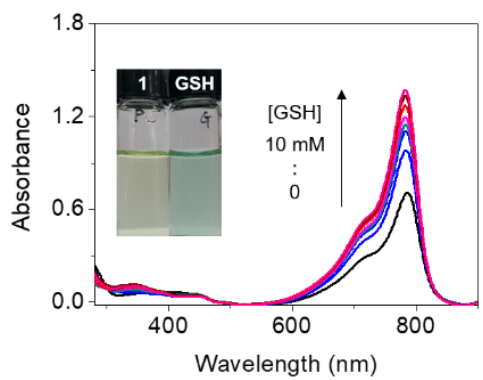

c)

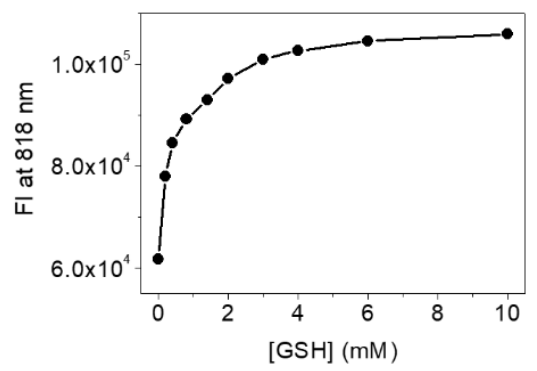

b)

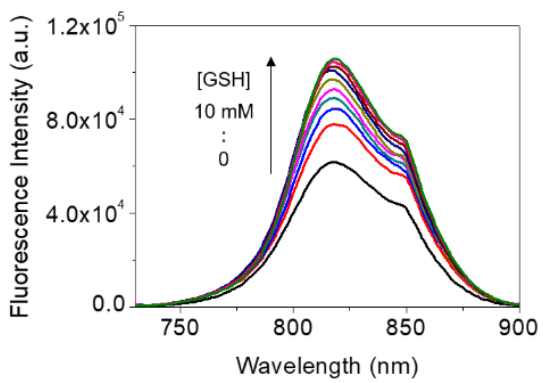

d)

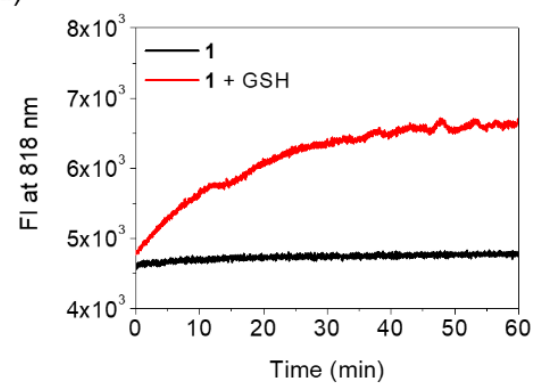

Figure 2. (a) UV-Vis absorption and (b) fluorescence spectra of $\mathbf{1}(10 \mu \mathrm{M})$ in presence of different concentrations of GSH (0-10 mM); (c) plot of fluorescence intensity at $818 \mathrm{~nm}$ of $\mathbf{1}$ vs. [GSH]; (d) time-dependent fluorescence change of $\mathbf{1}(10 \mu \mathrm{M})$ to $10 \mathrm{mM}$ of GSH. All data was obtained in HEPES buffer (10 mM, pH 7.4) containing 1\% $(v / v)$ of DMSO after incubation of $1 \mathrm{~h}$ at room temperature. The excitation wavelength was affected at $720 \mathrm{~nm}$.

In addition, the effect of the $\mathrm{pH}$ on probe 1's ability for GSH detection was also tested. In the presence of $10 \mathrm{mM}$ of GSH, 1 showed a distinct fluorescence increase at $818 \mathrm{~nm}$ in the pH range of 6-12 (Figure S8). It is noteworthy that the $\mathrm{pH}$ range of 6-12 is biologically relevant. Along with the results obtained from Figures 1 and 2, this indicated that probe $\mathbf{1}$ could provide a fluorescence increase at $818 \mathrm{~nm}$ towards GSH over Cys/Hcy in physiological conditions. We could think that it is ambiguous to judge whether the non-fluorescent cellular image of $\mathbf{1}$ is due to the absence of GSH or the presence of Cys/Hcy. However, in consideration of the physiological abundance of GSH compared to Cys/Hcy, the interference from Cys/Hcy would be insignificant. Thus, we believed that $\mathbf{1}$ could be used as a promising NIR fluorescent probe for the selective detection of GSH in human cells.

To gain insights into the reaction between probe 1 with GSH, Cys, and Hcy, we next performed mass analyses using $\mathbf{1}$ in the presence of GSH, Cys, and Hcy. In Figure 3, probe $\mathbf{1}$ showed a mass peak at $586 \mathrm{~m} / \mathrm{z}$. However, in the presence of GSH, 1 exhibited a mass peak at $782 \mathrm{~m} / \mathrm{z}$ corresponding to the formation of 1-GSH, while in the case of Hcy a mass peak at $610 \mathrm{~m} / z$ for 1-Hcy appeared. For Cys, the resulting intermediate 1-Cys did not seem to be ionized. However, as revealed in Figure 1, probe $\mathbf{1}$ showed quite different absorption and fluorescence changes for GSH and Cys/Hcy. Noticeably, 1 displayed the fluorescence centered at $818 \mathrm{~nm}$ in the absence and presence of GSH, whereas the fluorescence maximum wavelength was changed to $807 \mathrm{~nm}$ for Cys/Hcy. This can be derived from the formations of sulfur-substituted Cy7 for GSH (1-GSH) and amino-substituted Cy7 for Cys/Hcy (1-Cys/1-Hcy). Collectively, all photophysical changes and mass spectroscopic results supported the sensing mechanism of $\mathbf{1}$ for the selective detection of GSH over Cys/Hcy, as proposed in Scheme 1. 
a)

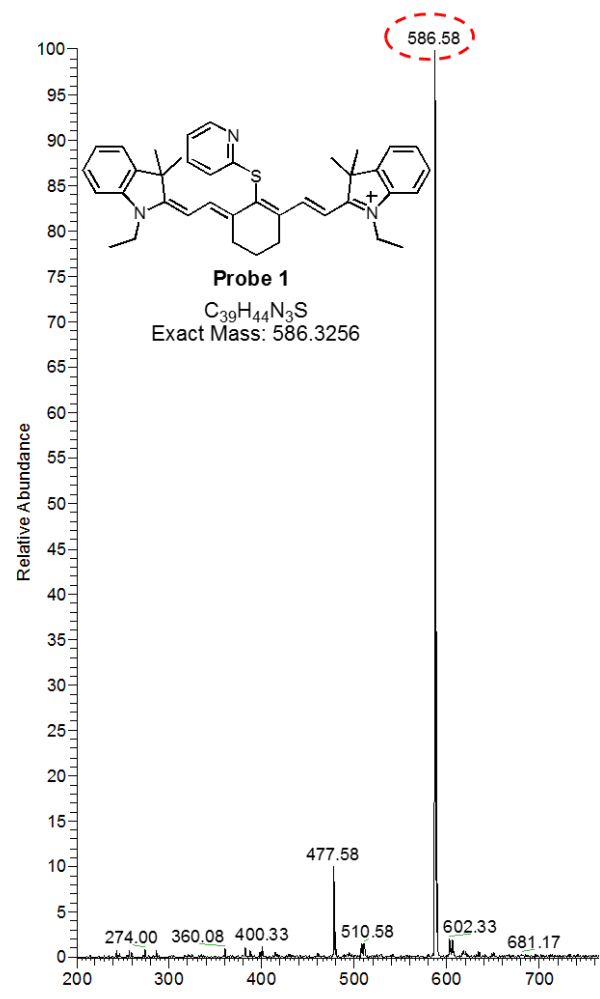

b)

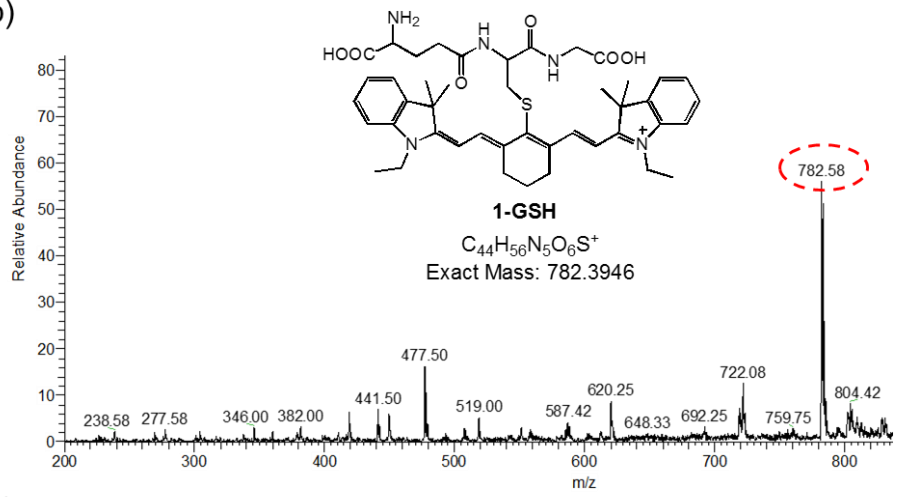

c)

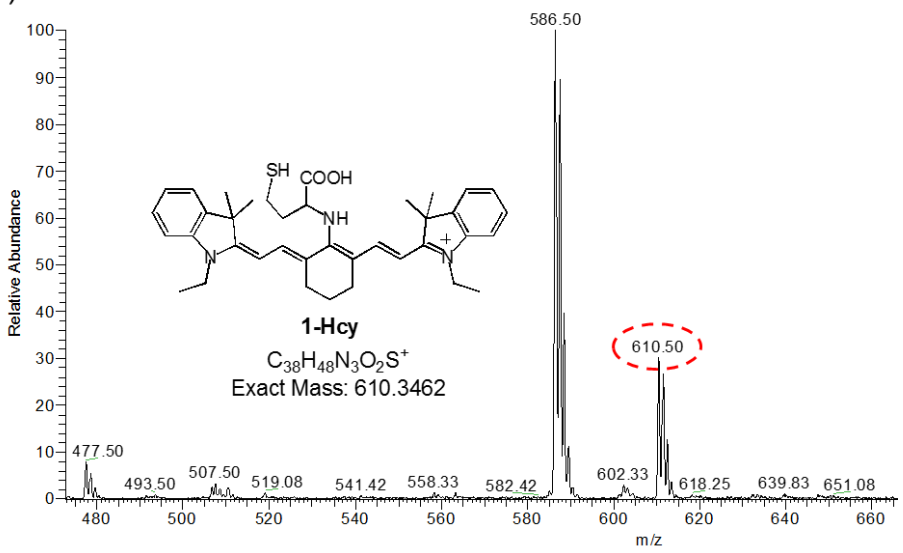

Figure 3. ESI-MS spectra of $\mathbf{1}$ (a) in the absence and presence of (b) GSH or (c) Hcy.

\subsection{Theoretical Study of Probe 1 and the Interaction with GSH and Cys}

The selectivity for GSH over other bio-thiols could be rationalized by DFT studies. Theoretical studies regarding the interaction between GSH and $\mathbf{1}$ were carried out using the dispersion-corrected range-separated $\omega$ B97XD functional, which was previously demonstrated to most accurately describe the sulfur bond distances in intermediates of thiol-Michael additions [41], at the $6-31+\mathrm{G}(\mathrm{d})$ level of theory in water. As can be seen in Figure 4 and Movie 1, GSH stabilizes the formation of the tetrahedral intermediate by the formation of a hydrogen bond between the glycine carboxylic acid and the pyridine. The formation of the hydrogen bond with the pyridine ring results in preorganization of GSH's sulfur atom near the Cy7 scaffold's reactive center, thus lowering the transition energy of the addition-elimination reaction, resulting in an accelerated reaction.
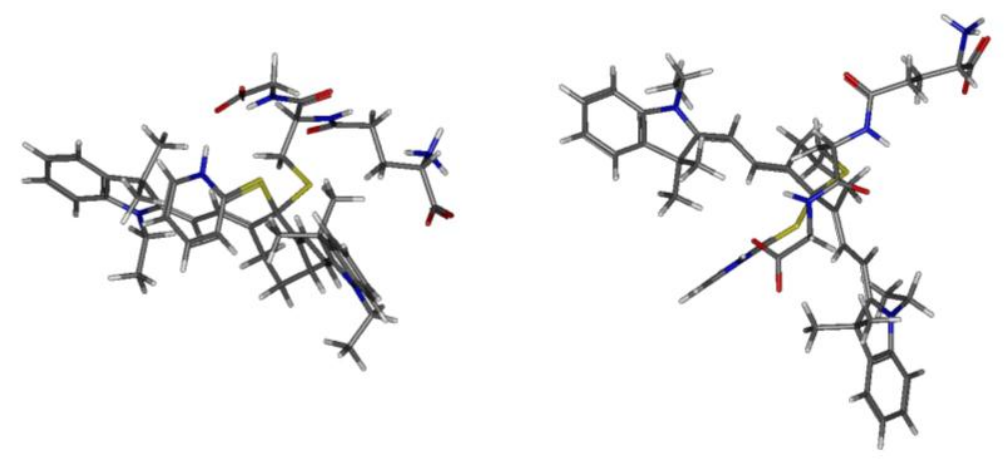

Figure 4. Optimized structure of the tetrahedral intermediate resulting from the nucleophilic addition of GSH to 1 (PCM- $w B 97 X D / 6-31+G(d))$. Left: side view, Right: top view. See Movie 1 for an animated version of the structure. 
Cysteine, on the other hand, would require an energetically unfavorable 10-membered ring in a similar preorganized tetrahedral state intermediate. Calculations predict only a small difference $\left(1.02 \mathrm{kCal} \cdot \mathrm{mol}^{-1}\right)$ between a cyclic and acyclic tetrahedral intermediate at the $\omega B 97 \mathrm{XD} / 6-31+\mathrm{G}(\mathrm{d})$ level of theory in water (Figure 5 and Movies 2-3), with the acyclic tetrahedral intermediate possessing the lowest energy. This small energy difference signifies the absence of a clear bias for either the cyclic or acyclic tetrahedral intermediate. As the addition step in the reaction of $\mathbf{1}$ with either GSH or Cys is the rate determining step (Scheme 1), the observed half-life of the reaction clearly shows the importance of the preorganization in the reaction kinetics (16 $\mathrm{min}$ vs. $27 \mathrm{~min}$, for GSH and Cys, respectively, see Figure 2 and Figure S7). Hcy, by contrast, exhibits a complex reaction kinetics behavior that was not further elucidated via calculations (Figure S7).
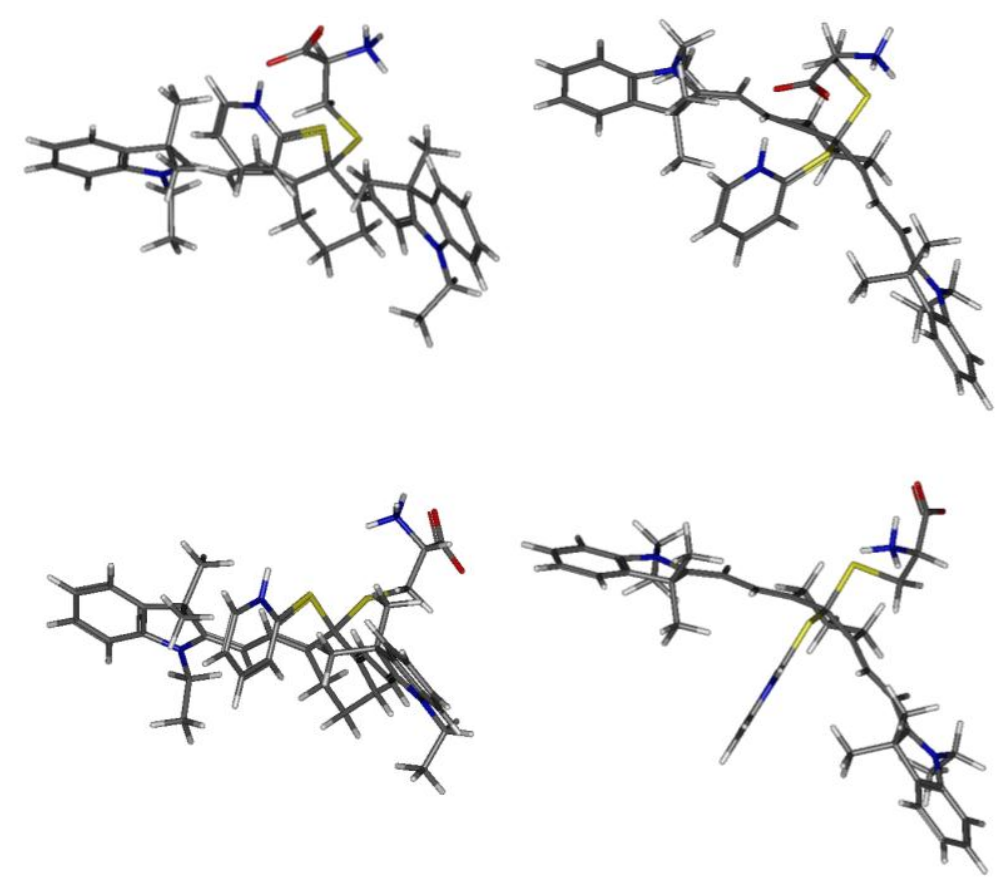

Figure 5. Optimized structure of the tetrahedral intermediate resulting from the nucleophilic addition of Cys to 1 (PCM- $\omega$ B97XD/6-31+G(d)), Top: cyclic intermediate, Bottom: acyclic intermediate, Left: side view, Right: top view. See Movies 2 and 3 for an animated version of both structures.

\subsection{Frontier Molecular Orbitals of $\mathrm{N}$ - and S-Substituted Cy7 Compounds}

The structures of $1-\mathbf{H}^{+}$, Cy7-SMe and Cy7-NHMe, as a model structure for the $S$ - and $\mathrm{N}$-substituted Cy7 dyes, respectively were optimized at the PBE0/6-311G $(2 \mathrm{~d}, \mathrm{p})$ level of theory using the PCM model of water. The optimized geometries and associated frontier orbitals are depicted in Figure S13.

\subsection{Fluorescence Imaging of the Cellular GSH Using Probe 1 in Live Human Cells}

We next tested the ability of probe 1 to image the cellular GSH by using confocal microscopy and the results are shown in Figure 6. Before applying 1 to bioimaging, cytotoxic effect of probe 1 was estimated in MDA-MB-231 cells by using CytoTox $96^{\circledR}$ Non-Radioactive Cytotoxicity Assay. The cell viability assays showed that up to $30 \mu \mathrm{M}, 1$ exhibited a very low cytotoxicity $(<6 \%)$ in cells (Figure S9). This result indicated that probe $\mathbf{1}$ has a potential for further biosensing applications. The MDA-MB-231 cells were incubated with probe $\mathbf{1}$ after the pretreatments of $N$-acetyl-L-cysteine (NAC) [42] as a ROS scavenger and buthionine sulfoximine (BSO) [43] as a GSH inhibitor (Figure 6a). Probe 1 displayed a very weak red fluorescence in intact cells without NAC and BSO (Figure 6b). However, probe 1 showed a strong red fluorescence in the NAC-treated cells, presumably due to the 
increased level of antioxidant GSH by the ROS scavenging. In contrast, in the case of BSO-treated cells, a significant decrease in the fluorescence intensity was observed, indicating the decreased GSH level. The relative fluorescence intensity of the images was also quantified in Figure 6c. Hence, we demonstrated that probe 1 could selectively react with GSH to give a fluorescence increase in the live human cells.

a)

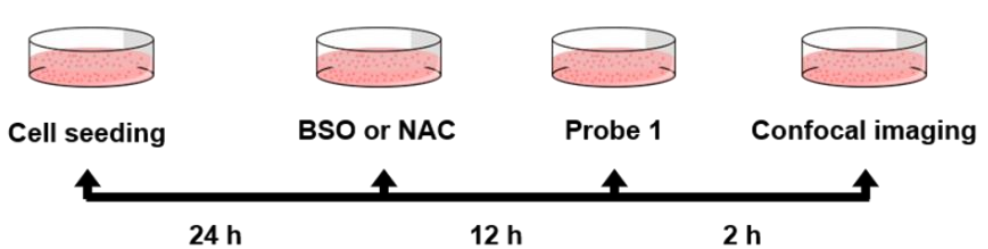

b)

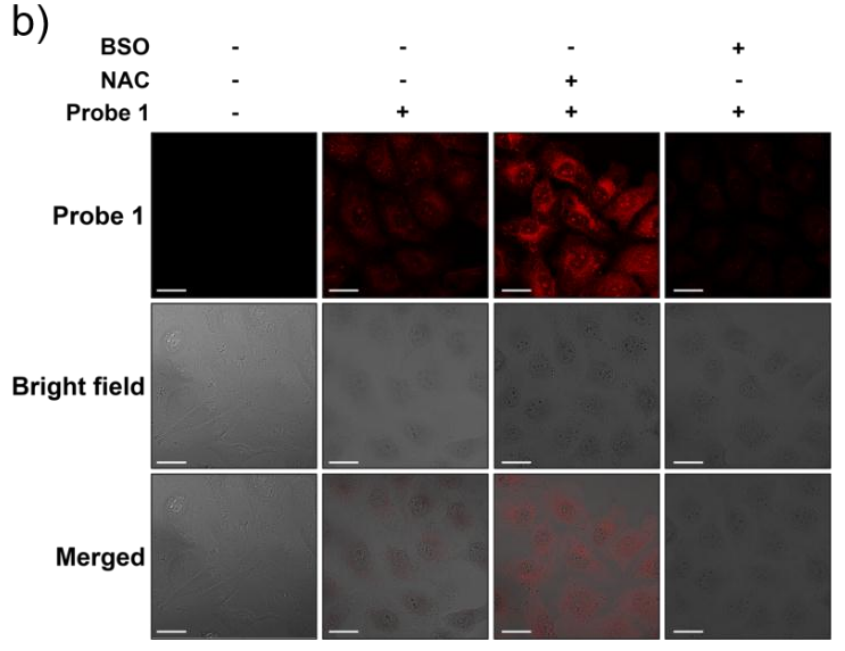

c)

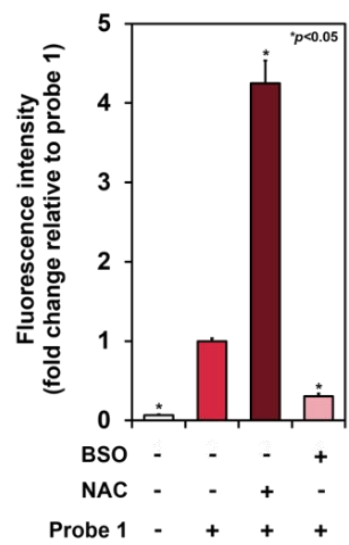

Figure 6. Confocal laser scanning microscopy images of $\mathbf{1}$ in MDA-MB-231 cells. (a) Preparation of cells for the confocal imaging using probe 1, buthionine sulfoximine (BSO), and N-acetyl-L-cysteine (NAC); (b) cells were pretreated with BSO (100 $\mu \mathrm{M}$; GSH inhibitor) or NAC (3 mM; ROS scavenger) for $12 \mathrm{~h}$ and then incubated with $\mathbf{1}(10 \mu \mathrm{M})$ for $2 \mathrm{~h}$. Scale bar $=20 \mu \mathrm{m}$; (c) the relative fluorescence intensity (fold change) of probe 1 was presented. The mean values of each group were quantified in 40 cells per treatment condition, after setting a common threshold for all images using Image J. Data are represented as fold change vs. the indicated reagents. The deep red bar indicated a fluorescence increase after NAC treatment, whereas pink bar represented a fluorescence decrease after BSO treatment. The percent fold changes are all significant $\left({ }^{*} p<0.05\right)$ based on a $t$-test.

\section{Conclusions}

We presented a highly selective NIR fluorescent probe (1) that can detect GSH selectively over Cys/Hcy under physiological conditions. We propose that in the presence of GSH and Hcy/Cys, the 2-mercaptopyridine of $\mathbf{1}$ is replaced by the thiolate of GSH to form the sulfur-substituted Cy7, 1-GSH, displaying a strong fluorescence at $818 \mathrm{~nm}$. However, for Hcy/Cys, 1 reacted with Hcy/Cys to form sulfur-substituted intermediates, and subsequently in a rearrangement reaction the amino groups of Hcy/Cys replaced the sulfur to give rise to the amino-substituted Cy7 dyes, 1-Hcy/1-Cy, exhibiting a weak fluorescence at $807 \mathrm{~nm}$. The sensing mechanism was thoroughly identified by photophysical studies, mass analyses, and computational calculations. In addition, we showed that the fluorescence increase of probe 1 was highly selective for GSH over Hcy, Cys, and other potential interferants such as biologically abundant ROS and metal ions. Moreover, we identified the ability of probe $\mathbf{1}$ for the selective detection of GSH in MDA-MB-231 cells using N-acetyl-L-cysteine (NAC; GSH inducer) or buthionine sulfoximine (BSO; GSH inhibitor). We envision that probe 1 will be a promising tool for 
imaging and monitoring of the GSH levels in living cells and will stimulate the design of new types of biologically relevant probes in the near future.

Supplementary Materials: The following are available online at http:/ /www.mdpi.com/1424-8220/18/9/2897/s1, Figure S1: UV-Vis absorption and fluorescence spectra of $\mathbf{1}(10 \mu \mathrm{M})$ in presence of reactive oxygen species such as ${ }^{\bullet} \mathrm{O}_{2}{ }^{-},{ }^{\bullet} \mathrm{OH}, \mathrm{t}-\mathrm{BuO}^{\bullet}, \mathrm{H}_{2} \mathrm{O}_{2}, \mathrm{t}-\mathrm{BuOOH}$, and $\mathrm{ClO}^{-}(1 \mathrm{mM}$, respectively). Figure S2: UV-Vis absorption and fluorescence spectra of $\mathbf{1}(10 \mu \mathrm{M})$ in presence of various anions such as various metal ions $\mathrm{Na}^{+}, \mathrm{K}^{+}, \mathrm{Mg}^{2+}, \mathrm{Ca}^{2+}$, $\mathrm{Fe}^{2+}, \mathrm{Co}^{2+}, \mathrm{Zn}^{2+}, \mathrm{Fe}^{3+}, \mathrm{Cu}^{2+}$, and $\mathrm{Cu}^{+}(1 \mathrm{mM}$, respectively). Figure S3: Absorption and fluorescence spectra of 1 $(10 \mu \mathrm{M})$ in presence of different concentrations of Cys $(0-3 \mathrm{mM})$. Figure S4: Absorption and fluorescence spectra of $1(10 \mu \mathrm{M})$ in presence of different concentrations of Hcy $(0-1 \mathrm{mM})$. Figure S5: Time-dependent fluorescence responses of $1(10 \mu \mathrm{M})$ toward (a) Cys and (b) Hcy $(10 \mathrm{mM})$ in HEPES buffer $(0.01 \mathrm{M}, \mathrm{pH} 7.4)$ containing $1 \%(v / v)$ of DMSO. Figure S6: The pH effect on fluorescence change of $\mathbf{1}(10 \mu \mathrm{M})$ in absence (black line) and presence (red line) of GSH (10 mM). Figure S7: ${ }^{1} \mathrm{H}$ NMR spectrum of $\mathbf{1}$ in DMSO- $d_{6}$. Figure S8: ${ }^{13} \mathrm{C}$ NMR spectrum of $\mathbf{1}$ in DMSO- $d_{6}$. Figure S9: ESI-MS spectrum of 1 . Figure S10: Isodensity surface $\left(0.03\right.$ e.bohr $\left.{ }^{-3}\right)$ of the HOMO (Left) and LUMO (Right) orbitals of a) Cy7-NHMe, b) Cy7-SMe and c) 1-H ${ }^{+}$at the PCM-PBE0/6-311G(2d,p) level of theory. Table S1: Coordinates of optimized structures.

Author Contributions: S.A.Y. performed spectroscopic experiments and prepared manuscript. W.K. synthesized all compounds and performed spectroscopic experiments and prepared manuscript. A.S. advised on the probe design, synthesis and prepared manuscript. P.V. carried out the theoretical study using DFT calculations and prepared manuscript. M.W. conducted the bioimaging experiments. M.H.L. supervised on the probe design and experiments, and manuscript editing.

Funding: This research was supported by Sookmyung Women's University Research Grants (1-1503-0152).

Conflicts of Interest: The authors declare no conflict of interest.

\section{References}

1. Forman, H.J.; Zhang, H.; Rinna, A. Glutathione: Overview of its protective roles, measurement, and biosynthesis. Mol. Asp. Med. 2009, 30, 1-2. [CrossRef] [PubMed]

2. Dalton, T.P.; Shertzer, H.G.; Puga, A. Regulation of gene expression by reactive oxygen. Annu. Rev. Pharmacol. Toxicol. 1999, 39, 67-101. [CrossRef] [PubMed]

3. Meister, A.; Anderson, M.E. Glutathione. Annu. Rev. Biochem. 1983, 52, 711-760. [CrossRef] [PubMed]

4. Estrela, J.M.; Ortega, A.; Obrador, E. Glutathione in cancer biology and therapy. Crit. Rev. Clin. Lab. Sci. 2006, 43, 143-181. [CrossRef] [PubMed]

5. Dooley, C.T.; Dore, T.M.; Hanson, G.T.; Jackson, W.C.; Remington, S.J.; Tsien, R.Y. Imaging dynamic redox changes in mammalian cells with green fluorescent protein indicators. J. Biol. Chem. 2004, 279, 22284-22293. [CrossRef] [PubMed]

6. Hussain, S.P.; Hofseth, L.J.; Harris, C.C. Radical causes of cancer. Nat. Rev. Cancer 2003, 3, 276-285. [CrossRef] [PubMed]

7. Jung, H.S.; Chen, X.; Kim, J.S.; Yoon, J. Recent progress in luminescent and colorimetric chemosensors for detection of thiols. Chem. Soc. Rev. 2013, 42, 6019-6031. [CrossRef] [PubMed]

8. Xu, K.; Qiang, M.; Gao, W.; Su, R.; Li, N.; Gao, Y.; Xie, Y.; Kong, F.; Tang, B. A near-infrared reversible fluorescent probe for real-time imaging of redox status changes in vivo. Chem. Sci. 2013, 4, 1079-1086. [CrossRef]

9. Liu, Z.; Zhou, X.; Miao, Y.; Hu, Y.; Kwon, N.; Wu, X.; Yoon, J. A reversible fluorescent probe for real-time quantitative monitoring of cellular glutathione. Angew. Chem. Int. Ed. 2017, 56, 5812-5816. [CrossRef] [PubMed]

10. Lee, J.H.; Sharma, A.; Jang, J.H.; Shin, W.S.; Lee, J.H.; Kim, J.S. Real time OFF-ON monitoring of glutathione (GSH) in living cell. J. Incl. Phenom. Macrocycl. 2015, 82, 117-122. [CrossRef]

11. Niu, L.Y.; Guan, Y.S.; Chen, Y.Z.; Wu, L.Z.; Tung, C.H.; Yang, Q.Z. BODIPY-based ratiometric fluorescent sensor for highly selective detection of glutathione over cysteine and homocysteine. J. Am. Chem. Soc. 2012, 134, 18928-18931. [CrossRef] [PubMed]

12. He, L.; Xu, Q.; Liu, Y.; Wei, H.; Tang, Y.; Lin, W. Coumarin-based turn-on fluorescence probe for specific detection of glutathione over cysteine and homocysteine. ACS Appl. Mater. Interfaces 2015, 7, 12809-12813. [CrossRef] [PubMed]

13. Niu, L.Y.; Guan, Y.S.; Chen, Y.Z.; Wu, L.Z.; Tung, C.H.; Yang, Q.Z. A turn-on fluorescent sensor for the discrimination of cystein from homocystein and glutathione. Chem. Commun. 2013, 49, 1294-1296. [CrossRef] [PubMed] 
14. Zhang, Y.; Shao, X.; Wang, Y.; Pan, F.; Kang, R.; Peng, F.; Huang, Z.; Zhang, W.; Zhao, W. Dual emission channels for sensitive discrimination of Cys/Hcy and GSH in plasma and cells. Chem. Commun. 2015, 51, 4245-4248. [CrossRef] [PubMed]

15. He, X.; Wu, X.; Shi, W.; Ma, H. Comparison of N-acetylcysteine and cysteine in their ability to replenish intracellular cysteine by a specific fluorescent probe. Chem. Commun. 2016, 52, 9410-9413. [CrossRef] [PubMed]

16. Yang, X.F.; Huang, Q.; Zhong, Y.; Li, Z.; Li, H.; Lowry, M.; Escobedo, J.O.; Strongin, R.M. A dual emission fluorescent probe enables simultaneous detection of glutathione and cysteine/homocysteine. Chem. Sci. 2014, 5, 2177-2183. [CrossRef] [PubMed]

17. Liu, J.; Sun, Y.Q.; Huo, Y.; Zhang, H.; Wang, L.; Zhang, P.; Song, D.; Shi, Y.; Guo, W. Simultaneous fluorescence sensing of Cys and GSH from different emission channels. J. Am. Chem. Soc. 2017, 136, 574-577. [CrossRef] [PubMed]

18. Yin, J.; Kwon, Y.; Kim, D.; Lee, D.; Kim, G.; Hu, Y.; Ryu, J.H.; Yoon, J. Cyanine-based fluorescent probe for highly selective detection of glutathione in cell cultures and live mouse tissues. J. Am. Chem. Soc. 2014, 136, 5351-5358. [CrossRef] [PubMed]

19. Lim, S.Y.; Hong, K.H.; Kim, D.I.; Kwon, H.; Kim, H.J. Tunable heptamethine-azo dye conjugate as an NIR fluorescent probe for the selective detection of mitochondrial glutathione over cysteine and homocysteine. J. Am. Chem. Soc. 2014, 136, 7018-7025. [CrossRef] [PubMed]

20. Yin, J.; Kwon, Y.; Kim, D.; Lee, D.; Kim, G.; Hu, Y.; Ryu, J.-H.; Yoon, J. Preparation of a cyanine-based fluorescent probe for highly selective detection of glutathione and its use in living cells and tissues of mice. Nat. Protoc. 2015, 10, 1742-1754. [CrossRef] [PubMed]

21. Sheng, X.; Chen, D.; Cao, M.; Zhang, Y.; Han, X.; Chen, X.; Liu, S.; Chen, H.; Yin, J. A near infrared cyanine-based fluorescent probe for highly selectively detecting glutathione in living cells. Chin. J. Chem. 2016, 34, 594-598. [CrossRef]

22. Lee, D.; Jeong, K.; Luo, X.; Kim, G.; Yang, Y.; Chen, X.; Kim, S.; Yoon, J. Near-infrared fluorescent probes for the detection of glutathione and their application in the fluorescence imaging of living cells and tumor-bearing mice. J. Mater. Chem. B 2018, 6, 2541-2546. [CrossRef]

23. Liu, C.-H.; Qi, F.-P.; Wen, F.-B.; Long, L.-P.; Liu, A.-J.; Yang, R.-H. Fluorescence detection of glutathione and oxidized glutathione in blood with a NIR-excitable cyanine probe. Methods Appl. Fluoresc. 2018, 6, 024001. [CrossRef] [PubMed]

24. Liu, J.; Sun, Y.Q.; Zhang, H.; Huo, Y.; Shi, Y.; Guo, W. Simultaneous fluorescent imaging of Cys/Hcy and GSH from different emission channels. Chem. Sci. 2014, 5, 3183-3188. [CrossRef]

25. Wang, X.; Lv, J.; Yao, X.; Li, Y.; Huang, F.; Li, M.; Yang, J.; Ruan, X.; Tang, B. Screening and investigation of a cyanine fluorescent probe for simultaneous sensing of glutathione and cysteine under single excitation. Chem. Commun. 2014, 50, 15439-15442. [CrossRef] [PubMed]

26. Sun, W.; Guo, S.; Hu, C.; Fan, J.; Peng, X. Recent development of chemosensors based on cyanine platforms. Chem. Rev. 2016, 116, 7768-7817. [CrossRef] [PubMed]

27. Lee, M.H. Bis(naphthalimide-piperazine)-based off-on fluorescent probe for acids. J. Fluoresc. 2016, 26, 807-811. [CrossRef] [PubMed]

28. Oushiki, D.; Kojima, H.; Terai, T.; Arita, M.; Hanaoka, K.; Urano, Y.; Nagano, T. Development and application of a near-infrared fluorescence probe for oxidative stress based on differential reactivity of linked cyanine dyes. J. Am. Chem. Soc. 2010, 132, 2795-2801. [CrossRef] [PubMed]

29. Sasaki, E.; Kojima, H.; Nishimatsu, H.; Urano, Y.; Kikuchi, K.; Hirata, Y.; Nagano, T. Highly sensitive near-infrared fluorescent probes for nitric oxide and their application to isolated organs. J. Am. Chem. Soc. 2005, 127, 3684-3685. [CrossRef] [PubMed]

30. Chai, J.-D.; Head-Gordon, M. Long-range corrected hybrid density functionals with damped atom-atom dispersion corrections. Phys. Chem. Chem. Phys. 2008, 10, 6615-6620. [CrossRef] [PubMed]

31. Raghavachari, K.; Binkley, J.S.; Seeger, R.; Pople, J.A. Self-Consistent Molecular Orbital Methods. XX. Basis set for correlated wave-functions. J. Chem. Phys. 1980, 72, 650-654.

32. McLean, A.D.; Chandler, G.S. Contracted Gaussian-basis sets for molecular calculations. 1. 2nd row atoms, $\mathrm{Z}=11$ - 18. J. Chem. Phys. 1980, 72, 5639-5648. [CrossRef] 
33. Clark, T.; Chandrasekhar, J.; Spitznagel, G.W.; von Ragué Schleyer, P. Efficient diffuse function-augmented basis-sets for anion calculations. 3. The 3-21 + G basis set for 1st-row elements, Li-F. J. Comp. Chem. 1983, 4, 294-301. [CrossRef]

34. Frisch, M.J.; Pople, J.A.; Binkley, J.S. Self-Consistent Molecular Orbital Methods. 25. Supplementary Functions for Gaussian Basis Sets. J. Chem. Phys. 1984, 80, 3265-3269. [CrossRef]

35. Lipparini, F.; Scalmani, G.; Mennucci, B.; Cances, E.; Caricato, M.; Frisch, M.J. A variational formulation of the polarizable continuum model. J. Chem. Phys. 2010, 133, 014106. [CrossRef] [PubMed]

36. Frisch, M.J.; Trucks, G.W.; Schlegel, H.B.; Scuseria, G.E.; Robb, M.A.; Cheeseman, J.R.; Scalmani, G.; Barone, V.; Petersson, G.A.; Nakatsuji, H.; et al. Gaussian 16; Gaussian Inc.: Wallingford, CT, USA, 2016.

37. Adamo, C.; Barone, V. Toward reliable density functional methods without adjustable parameters: The PBE0 model. J. Chem. Phys. 1999, 110, 6158-6169. [CrossRef]

38. Allouche, A.R. Gabedit-A graphical user interface for computational chemistry softwares. J. Comp. Chem. 2011, 32, 174-182. [CrossRef] [PubMed]

39. Li, Y.; Sun, Y.; Li, J.; Su, Q.; Yuan, W.; Dai, Y.; Han, C.; Wang, Q.; Feng, W.; Li, F. Ultrasensitive near-infrared fluorescence-enhanced probe for in vivo nitroreductase imaging. J. Am. Chem. Soc. 2015, 137, 6407-6416. [CrossRef] [PubMed]

40. Park, S.Y.; Kim, W.; Park, S.H.; Han, J.; Lee, J.; Kang, C.; Lee, M.H. An endoplasmic reticulum-selective ratiometric fluorescent probe for imaging a copper pool. Chem. Commun. 2017, 53, 4457-4460. [CrossRef] [PubMed]

41. Smith, J.M.; Jami Alahmadi, Y.; Rowley, C.N. Range-separated DFT functionals are necessary to model thio-Michael additions. J. Chem. Theory Comput. 2013, 9, 4860-4865. [CrossRef] [PubMed]

42. Witko-Sarsat, V.; Gausson, V.; Nguyen, A.T.; Touam, M.; Drüeke, T.; Santangelo, F.; Descamps-Latscha, B. AOPP-induced activation of human neutrophil and monocyte oxidative metabolism: A potential target for $\mathrm{N}$-acetylcysteine treatment in dialysis patients. Kidney Int. 2003, 64, 82-91. [CrossRef] [PubMed]

43. Du, Z.X.; Zhang, H.Y.; Meng, X.; Guan, Y.; Wang, H.Q. Role of oxidative stress and intracellular glutathione in the sensitivity to apoptosis induced by proteasome inhibitor in thyroid cancer cells. BMC Cancer 2009, 9, 56-66. [CrossRef] [PubMed] 